\title{
Antipsychotic treatments; focus on lurasidone
}

\section{Tomiki Sumiyoshi*}

Neurocognition and Pharmacology Laboratory, Department of Neuropsychiatry, University of Toyama Graduate School of Medicine and Pharmaceutical Sciences, Toyama, Japan

Edited by:

Maarten Van Den Buuse, Mental

Health Research Institute, Australia

Reviewed by:

Jared $W$. Young, University of

California, San Diego, USA

Anand Gururajan, The Florey

Institute of Neuroscience and

Mental Health, Australia

*Correspondence:

Tomiki Sumiyoshi, Neurocognition and Pharmacology Laboratory,

Department of Neuropsychiatry,

University of Toyama Graduate

School of Medicine and

Pharmaceutical Sciences, 2630

Sugitani, Toyama 930-0194, Japan

e-mail: tomikisumiyoshi840@

hotmail.com
The introduction of atypical antipsychotic drugs (AAPDs), or second-generation antipsychotics, with clozapine as the prototype, has largely changed the clinicians' attitudes toward the treatment of mental illnesses including, but not limited to schizophrenia. Initially, there was optimism that AAPDs would be superior over typical antipsychotic drugs (TAPDs), or first-generation antipsychotic drugs, in terms of efficacy in various phenomenological aspects, including cognitive impairment, and less likelihood of causing adverse events. However, these views have been partly challenged by results from recent meta-analysis studies. Specifically, cardio-metabolic side effects of AAPDs, in spite of a relative paucity of extrapyramidal symptoms, may sometimes limit the use of these agents. Accordingly, attempts have been made to develop newer compounds, e.g., lurasidone, with the aim of increasing efficacy and tolerability. Further investigations are warranted to determine if a larger proportion of patients will be benefitted by treatment with AAPDs compared to TAPDs in terms of remission and recovery.

Keywords: antipsychotic drugs, second generation, schizophrenia, effectiveness, side effects, remission

\section{INTRODUCTION}

Antipsychotic drugs have been considered to represent a series of compounds to treat specific symptoms of schizophrenia, i.e., positive (delusions, hallucinations, disorganized thoughts, and etc.) and negative (blunt affect, avolition, social withdrawal, and etc.) symptoms. Conventional, or "typical," antipsychotic drugs (TAPDs) exert antipsychotic effects at doses that cause extrapyramidal motor side effects due to dopamine (DA)- $\mathrm{D}_{2}$ receptor blocking properties. Selective actions on psychotic symptoms, with less chance to cause extrapyramidal side effects (EPS), have become possible with the advent of newer class agents, so-called "atypical antipsychotic drugs (AAPDs)" (Meltzer, 1991a). In addition to positive symptoms of schizophrenia, which antipsychotic drugs were initially expected to ameliorate, there is a recent trend to use AAPDs for other psychiatric diseases, e.g., mood disorders, as discussed below.

The development of antipsychotic drugs has been coupled with more intricate theories on the pathophysiology of schizophrenia (Meltzer, 1991b). For example, hyperactivity of DA neurons projecting to the limbic regions, e.g., nucleus accumbens and amygdala, has been shown to be associated with positive symptoms, while a decrease in DA activity in the prefrontal cortex has been considered to cause negative symptoms (Seeman et al., 2006). On the other hand, phencyclidine (PCP), an antagonist at the N-methyl-D-aspartate (NMDA) type glutamate receptor, has been found to produce schizophrenia-like symptoms. This observation led to the glutamate hypothesis of the disease, which is proposed to be linked to the DA hypothesis (Toru et al., 1994).

This article aims to provide theoretical issues on AAPDs in relation to efficacy for treating psychotic symptoms and cognition, as well as safety and tolerability. Specifically, cognitive benefits of lurasidone, a novel AAPD are a focus of this paper.
Based on previous discussions (Oliveira et al., 2009; Melnik et al., 2010; Meltzer, 2013) and updated information on these issues, the author present a hypothesis for future directions of therapeutics of schizophrenia and related disorders.

\section{HISTORY OF ANTIPSYCHOTIC DRUGS}

The serendipitous discovery of the ability of chlorpromazine to treat psychomotor excitation of schizophrenia confirmed the concept that the illness is a medical entity related to brain chemistry (Delay and Deniker, 1955) (Figure 1). The subsequent development of haloperidol, also inhibiting psychomotor symptoms, provided a clue to the pharmacological target shared by most antipsychotic agents; the DA- $\mathrm{D}_{2}$ receptor (Seeman et al., 2006). This property of TAPDs (Figure 2) is associated with the incidence of motor dysfunction, e.g., parkinsonisms, akashisia, dystonia and dyskinesia, as well as endocrinological derangements, e.g., hyperprolactinemia (Sumiyoshi, 2008).

The search for improved medications for schizophrenia led to the implementation of clozapine, the prototype of AAPDs (Kane et al., 1988; Meltzer, 1989). Clozapine shows strong blocking effects for serotonin (5-HT)-5-HT $2 \mathrm{~A}$ and DA- $\mathrm{D}_{4}$ receptors relative to $D_{2}$ receptors, which is thought to underlie the ability of this compound to ameliorate not only positive symptoms, but also negative symptoms to some extent, without causing EPS (Meltzer et al., 1989; Stockmeier et al., 1993; Sumiyoshi et al., 1995).

The experience with clozapine prompted the development of a series of AAPDs with relatively potent $5-\mathrm{HT}_{2 \mathrm{~A}}$ vs. $\mathrm{D}_{2}$ receptor blocking effects, in an attempt to decrease the likelihood of EPS and elevation of plasma prolactin (pPRL) levels. Consequently, risperidone, olanzapine, quetiapine, aripiprazole, ziprasidone, have been developed (Figure 3). In addition, paliperidone, an active metabolite of risperidone, as well as lurasidone, asenapine 


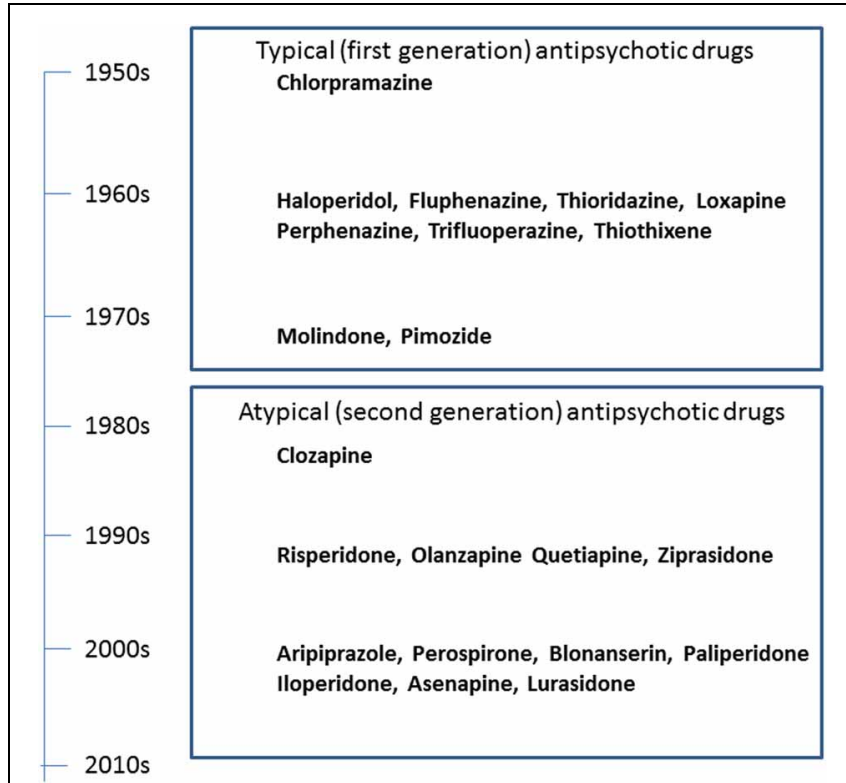

FIGURE 1 | Historical overview of the development of antipsychotic drugs.

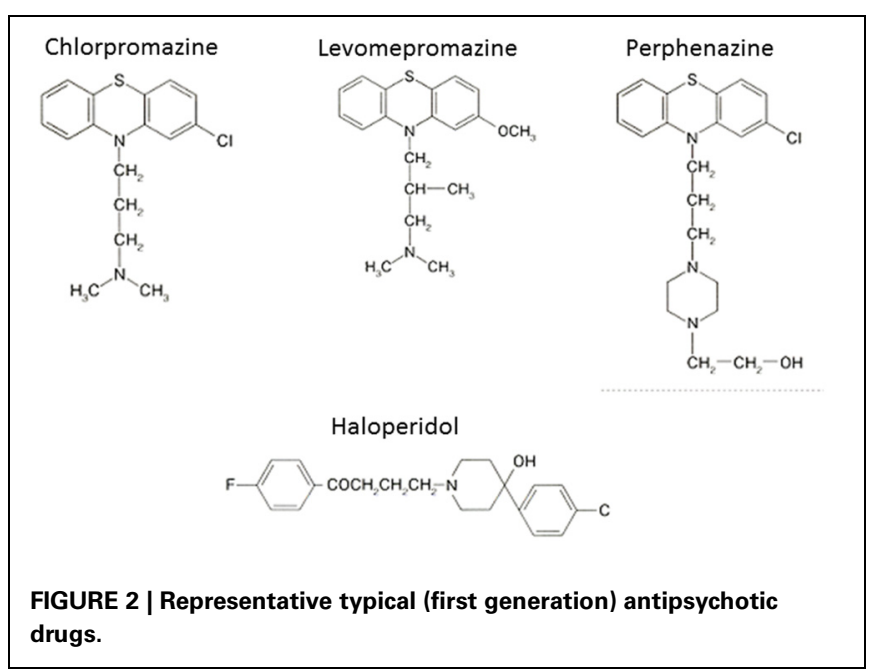

and iloperidone (in the USA), amisulpiride (in Europe), and perospirone and blonanserin (in Japan), have enriched the choice of AAPDs (Figure 4).

\section{PHARMACOLOGY}

The above AAPDs, except amisulpiride, a relatively selective $\mathrm{D}_{2} / \mathrm{D}_{3}$ ligand, share a property of relatively high $5-\mathrm{HT}_{2 \mathrm{~A}}$ vs. $\mathrm{D}_{2}$ receptor affinity (Meltzer et al., 1989; Stockmeier et al., 1993; Sumiyoshi et al., 1995). Some of them, e.g., clozapine, olanzapine and quetiapine, also exhibit considerable affinities for $\mathrm{D}_{1}$, histamine $H_{1}$, adrenalin- $\alpha_{1}$, and muscarinic- $M_{1}$, receptors, and etc. (Meltzer et al., 2003; Newman-Tancredi and Kleven, 2011). Pharmacologic profiles for representative AAPDs can be summarized as eliciting relatively strong affinities for $5-\mathrm{HT}_{1 \mathrm{~A}}, 5-\mathrm{HT}_{2} \mathrm{C}$

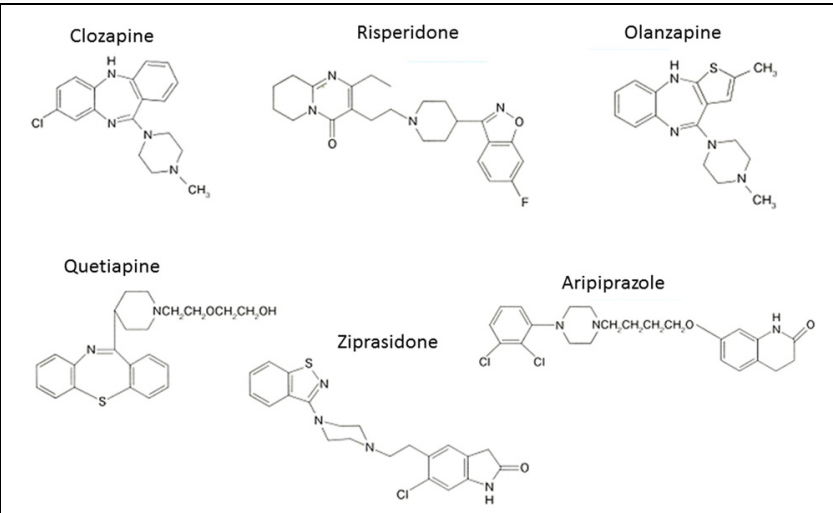

FIGURE 3 | Atypical (second generation) antipsychotic drugs widely used.

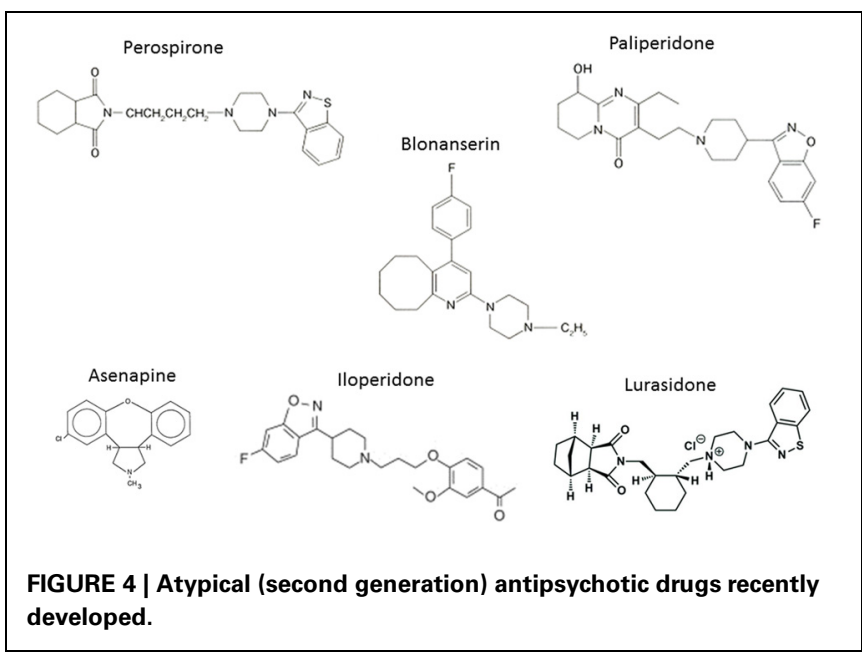

and NA- $\alpha_{1}$ receptors, in addition to $5-\mathrm{HT}_{2 \mathrm{~A}}$ and $\mathrm{D}_{2}$ receptors, as indicated in Figure 5 (Newman-Tancredi and Kleven, 2011).

Other common pharmacologic features of AAPDs include the ability to increase extracellular concentrations of DA and acetylcholine in the prefrontal cortex, as measured by in vivo microdialysis (Kuroki et al., 1998; Ichikawa et al., 2002). This property has been associated with beneficial effects of these compounds on negative symptoms and cognitive impairment (Kuroki et al., 1998; Ichikawa et al., 2002; Meltzer et al., 2003). It should be noted that the mechanisms of action of antipsychotic drugs were largely derived from studies using animal models of behavioral abnormalities, e.g., sensorimotor gating deficits (Swerdlow et al., 1994).

\section{EFFICACY}

\section{GENERAL VIEWS}

A recent meta-analysis comparing AAPDs and TAPDs in the treatment of chronic schizophrenia suggests the advantage of clozapine, risperidone, olanzapine, and amisulpiride over TAPDs (Leucht et al., 2009b) for overall efficacy. However, the effect sizes were small (Leucht et al., 2009b), and specific side effects of these agents, e.g., hyperprolactinemia for risperidone and weight 


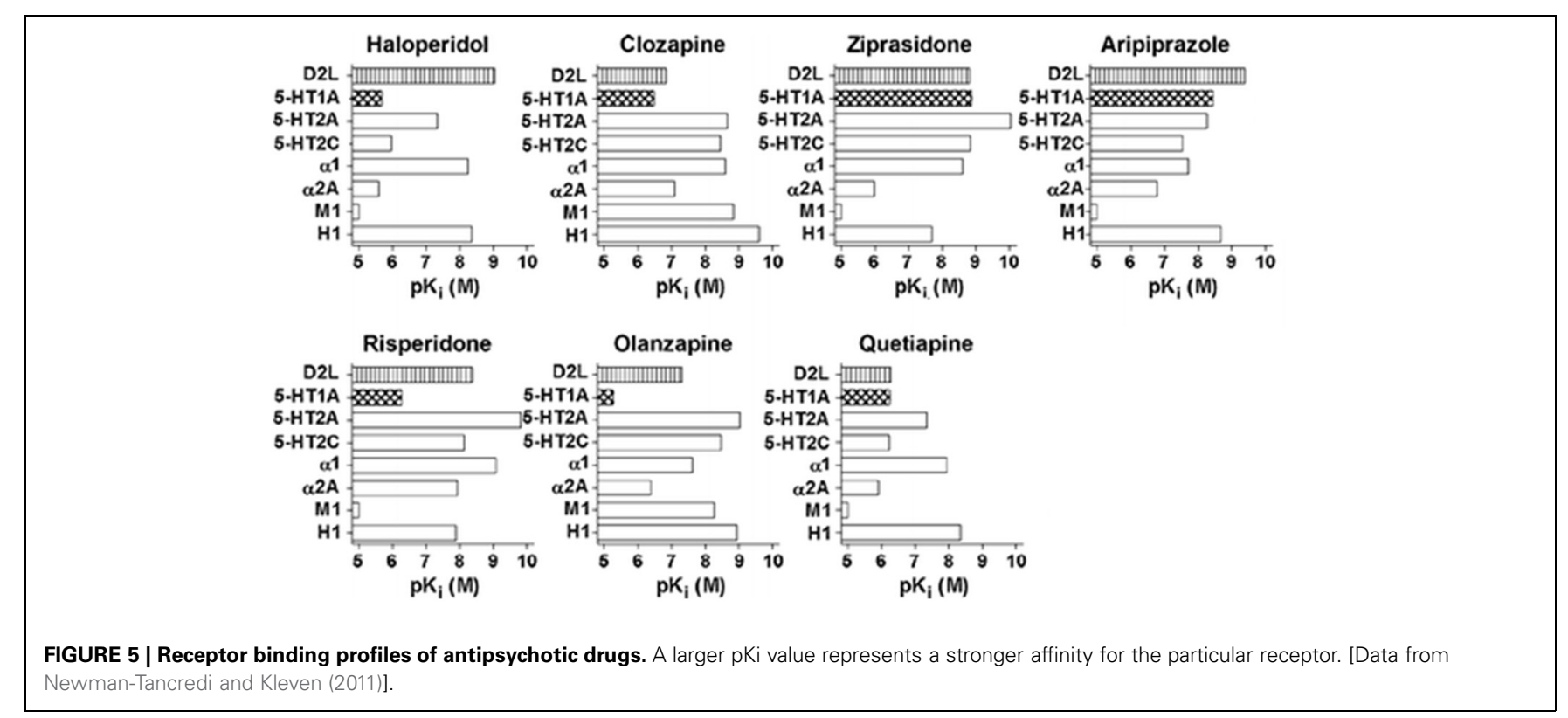

gain/metabolic syndrome for olanzapine and clozapine, should be considered (Zhang et al., 2013).

For first-episode patients, Zhang et al. (2013) conducted a meta-analysis of acute, randomized trials with AAPDs vs. TAPDs comparison. The results indicate AAPDs as a whole showed superior efficacy for negative symptoms, and that olanzapine and amisulpiride specifically showed greater benefits than TAPDs (Zhang et al., 2013).

\section{COGNITION}

Patients with schizophrenia demonstrate a 1-2.5 standard deviation decline in performance on neuropsychological tests of a range of cognitive domains, e.g., several types of memory, executive function (planning, flexibility of thinking and etc.), attention/information processing, verbal fluency, and motor function (Harvey and Keefe, 1997; Keefe et al., 2004) (Figure 6). Cognitive impairment in schizophrenia has been suggested to largely determine the outcome for patients (Green, 1996; Addington and Addington, 2000; Green et al., 2000).

Although TAPDs, e.g., haloperidol, exert detrimental influence on cognition in healthy subjects (Saeedi et al., 2006; Veselinovic et al., 2013), there has been controversy about whether AAPDs are more advantageous over TAPDs for its enhancement in schizophrenia (Meltzer et al., 1999; Woodward et al., 2005; Goldberg et al., 2007). Results of the large scale trials, such as the Clinical Antipsychotic Trials of Intervention Effectiveness (CATIE) study, suggest AAPDs may not elicit superiority over TAPDs on cognition (Keefe et al., 2007). However, observations in the CATIE trial should be interpreted with caution, as it did not include a placebo arm, and the results were from chronic patients (Lieberman et al., 2005).

Besides a trial with chronic schizophrenia (Weickert et al., 2003), there has been little study on cognition in acute schizophrenia that includes a placebo arm. Accordingly, we recently reported a double-blind placebo-controlled trial to

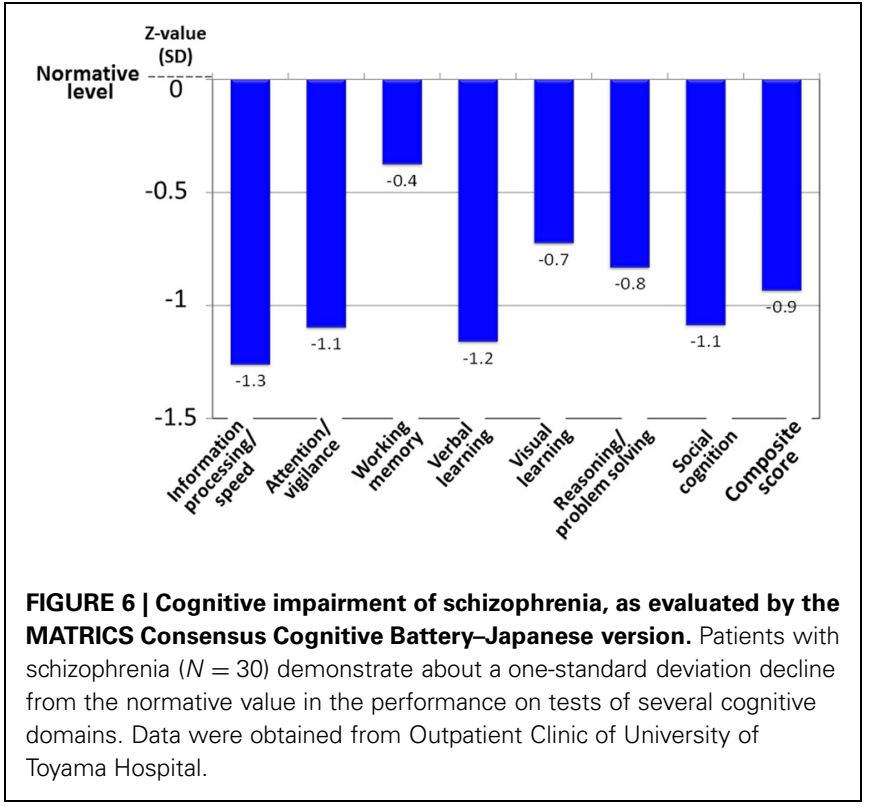

examine the effect of lurasidone, a novel AAPD (Meyer et al., 2009; Sumiyoshi et al., 2013), on cognitive performance in patients with acute psychosis, followed by a long-term extension study (Sumiyoshi et al., 2013) (Figure 7).

In the acute study patients were randomized to receive treatment with lurasidone $80 \mathrm{mg}(N=125), 160 \mathrm{mg}(N=121)$, quetiapine $600 \mathrm{mg}(N=120)$, or placebo $(N=122)$. Subjects who completed the 6-week treatment were eligible for the double-blind extension study to receive a once-daily flexible dose of lurasidone $(40-160 \mathrm{mg} /$ day; $N=151)$ or quetiapine (200-800 mg/day; $N=85)$. Subjects who received placebo in the acute study were administered lurasidone $(40-160 \mathrm{mg} /$ day; $N=56)$. Cognitive performance was examined with the computerized CogState battery (Pietrzak et al., 2009) at baseline 

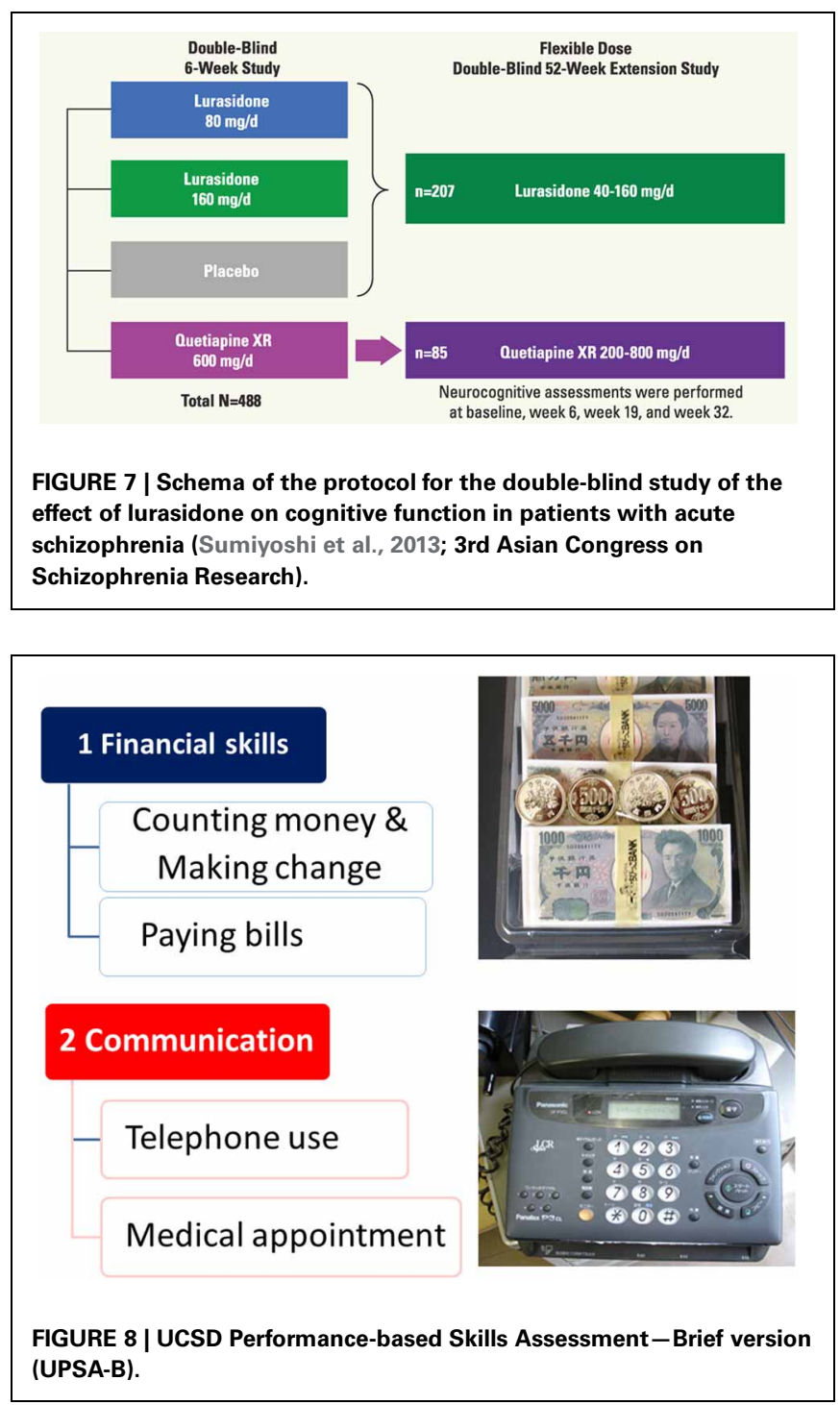

of the acute phase, and after 6,19 , and 32 weeks of treatment. The battery consists of eight tasks that measure verbal learning, speed of processing, attention/vigilance, visual working memory, visual memory, spatial working memory, reasoning and problem solving, and social cognition (Pietrzak et al., 2009). The average of standardized $Z$-scores from each task was used as the valid neurocognitive composite $Z$-score. Functional capacity was evaluated with UCSD Performance-based Skills Assessment-Brief version (UPSA-B) (Mausbach et al., 2011) (Figure 8).

At 6 weeks, the change in the neurocognitive composite $Z$-score did not differ significantly among all groups in intentto-treat population $(N=488)$. In the evaluable analysis sample $(N=267)$ according to pre-specific criteria, lurasidone, at $160 \mathrm{mg}$, was superior to both placebo $(p<0.05, d=0.367)$ and quetiapine XR $(p<0.05, d=0.411)$ (Figure 9). Patients with any of the active treatments elicited greater improvement in the UPSA-B score than did those given placebo. In the 6-month extension study, lurasidone, at flexible doses of $40-160 \mathrm{mg} /$ day,

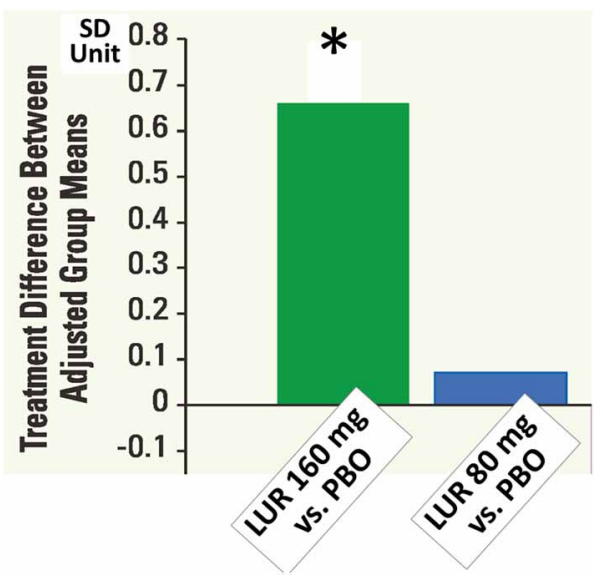

FIGURE 9 | Cognitive composite z-scores in double-blind 6-week acute phase study of lurasidone (LUR) relative to placebo (PBO). Data are based on LOCF analysis of CogState composite score (standardized $z$-score) at week 6 in the evaluable-test sample set $(N=267) .{ }^{*} P<0.05$, ANCOVA adjusted for baseline and pooled center.

showed a significantly greater cognitive benefit compared to quetiapine XR, at flexible doses of $200-800 \mathrm{mg} /$ day, at week 32 $(p<0.01, d=0.57)$. Mixed effects model analysis demonstrated significant cross-sectional and longitudinal relationship between the cognitive composite score and UPSA-B total score.

Data from the placebo-controlled acute phase study provide robust evidence for the ability of lurasidone to enhance cognitive function and functional capacity in patients with schizophrenia. The relatively high rate of subjects who did not provide evaluable data may be associated with awareness of illness, or insight, of study participants (Harvey et al., 2013).

In spite of some beneficial effects, discussed above, no treatments have been approved for treating cognitive or negative symptoms in schizophrenia. Therefore, further efforts are required in this area.

\section{MOOD DISORDERS}

Recently, AAPDs have been used for a variety of psychiatric conditions, in addition to schizophrenia, e.g., mood disorders, although the mechanisms underlying their therapeutic effects remain unknown. So far, the Food and Drug Administration in the US has approved indications for olanzapine, quetiapine, risperidone, aripiprazole, and asenapine to treat bipolar disorder, as shown in Table 1 (Bobo, 2013; Spielmans et al., 2013). As for major depressive disorder, a recent meta-analysis (Spielmans et al., 2013) indicates adjunctive treatment with AAPDs, e.g., aripiprazole, olanzapine/fluoxetine, quetiapine, or risperidone, is effective in reducing depressive symptoms, with small-tomoderate effect sizes. Olanzapine, quetiapine, and aripiprazole are indicated to treat major depression (Spielmans et al., 2013), as shown in Table 2.

\section{OTHER DISEASES}

Some AAPDs have been suggested to ameliorate part of symptoms or caregiver's burden in other conditions, such as 
Table 1 | Year of approval by FDA of AAPDs for bipolar disorder.

\begin{tabular}{llll}
\hline & $\begin{array}{l}\text { Acute mania/ } \\
\text { mixed episodes }\end{array}$ & $\begin{array}{l}\text { Bipolar disorder } \\
\text { maintenance Tx }\end{array}$ & $\begin{array}{l}\text { Acute bipolar } \\
\text { depression }\end{array}$ \\
\hline Olanzapine & 2000 & 2004 & $2003^{\mathrm{a}}$ \\
Quetiapine & 2004 & $2004^{\mathrm{b}}$ & 2008 \\
Risperidone & 2003 & $2009^{\mathrm{c}}$ & \\
Aripiprazole & 2004 & 2004 & $2013^{\mathrm{d}}$ \\
Asenapine & 2007 & & 2 \\
Lurasidone & & &
\end{tabular}

a Olanzapine/flluoxetine combination.

${ }^{b}$ In combination with valproate/lithium.

${ }^{c}$ Depot formulation.

${ }^{d}$ Both for monotherapy and in combination with valproate/lithium.

Table 2 | Year of approval for major depression.

\begin{tabular}{lcc}
\hline & Add-on to antidepressants & Monotherapy \\
\hline Quetiapine & 2009 & Applying \\
Olanzapine & $2009^{a}$ & \\
Aripiprazole & 2007 & \\
\hline
\end{tabular}

a Olanzapine/flluoxetine combination.

Alzheimer's disease (Mohamed et al., 2012), Huntington disease (Adam and Jankovic, 2008), Parkinson's disease (Friedman, 2011), and Tourette's syndrome (Maher and Theodore, 2012). For example, AAPDs have been reported to reduce psychosis, agitation, and/or aggressive behavior in Alzheimer's disease and Huntington disease (Mohamed et al., 2012; Adam and Jankovic, 2008). Clozapine, as well as quetiapine to some extent, has been shown to be effective in controlling psychotic symptoms of Parkinson's disease (Friedman, 2011).

\section{TOLERABILITY}

Compared to TAPDs, AAPDs have been associated with reduced risk of EPS and tardive dyskinesia, although the latter compounds may more frequently induce weight gain and cardio-metabolic side effects in schizophrenia (De Hert et al., 2012a). Further, some large scale studies with chronic patients did not find noticeable differences in efficacy between the two antipsychotic classes (Lieberman et al., 2005; Jones et al., 2006; Leucht et al., 2009a), raising a question about the advantage of AAPDs. However, there is a suggestion that higher benefit/risk ratios for AAPDs would be expected in acute patients compared with chronic patients (Zhang et al., 2013). In fact, a recent meta-analysis (Zhang et al., 2013) indicates olanzapine, amisulpiride, risperidone and quetiapine, elicit superior efficacy, greater treatment persistence and less EPS than TAPDs. These authors also found greater weight increase and metabolic changes for some of these AAPDs, such as olanzapine (Zhang et al., 2013).

These lines of evidence prompted the development of newer antipsychotic drugs with minimal adverse events associated with the above AAPDs, e.g., weight gain, lipid metabolism, cardiovascular risk, and glucose intolerance. Accordingly, the FDA approved iloperidone and asenapine in 2009, followed

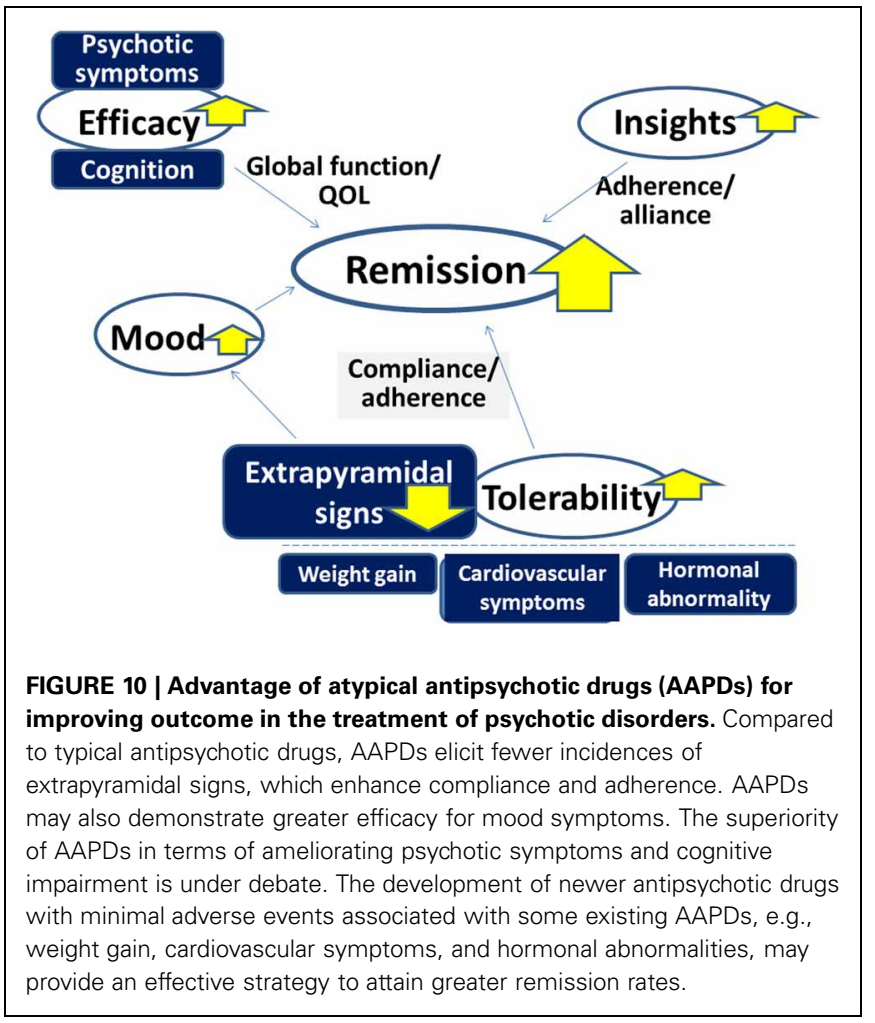

by lurasidone in 2010, for the treatment of adults with acute schizophrenia. De Hert et al. (2012b) conducted a systematic review and exploratory meta-analysis of these new AAPDs together with paliperidone in the treatment of schizophrenia and bipolar disorder. The findings suggest a relatively greater tolerability for lurasidone in comparison with placebo, and indicate the need for further controlled studies comparing the newer agents with other antipsychotic drugs currently available (De Hert et al., 2012b).

\section{PERSPECTIVES}

In the pursuit of novel therapeutics, critical issues to be addressed, or "unmet needs," include (1) treatment-resistant patients, (2) prevention of psychosis, and (3) remission/recovery. There have been some suggestions for the former two, e.g., clozapine for treatment-resistant schizophrenia (Kane et al., 1988; Meltzer, 1989), and risperidone and olanzapine for prevention (McGorry et al., 2002; McGlashan et al., 2006). On the other hand, there seems to be a relative paucity of information on whether AAPDs increase remission in schizophrenia (Takeuchi et al., 2012), due, partly, to the limited number of valid assessment methods (Alaqeel and Margolese, 2012).

Such measures include the Remission in Schizophrenia Working Group (RSWG) criteria (Andreasen et al., 2005), which has been developed to operationally define symptomatic remission. Using the RSWG criteria, Alaqeel et al. (2013) recently conducted a meta-analysis to compare remission rates between AAPD and TAPD treatments. Results from four eligible studies, with 3433 schizophrenia patients, suggest AAPDs are associated with a 1.46 increased probability of attaining remission relative to TAPDs (Alaqeel et al., 2013). The lower dropout rate with AAPDs 
may explain the modest but significant increase in the rate of enduring symptomatic remission, which deserves further study.

\section{CONCLUSIONS}

Antipsychotic drugs play a major role in the treatment of schizophrenia and related disorders. However, there remain a number of issues to be solved to more effectively improve clinical practice, e.g., dealing with treatment-resistant patients. As discussed, some evidence suggests the superiority of AAPDs as a group over TAPDs in terms of compliance/adherence, although controversy exists. At least, it is legitimate to confirm that AAPDs elicit lower incidence of EPS compared to TAPDs. Accordingly, AAPDs may also demonstrate greater efficacy for mood symptoms, and less likelihood to cause secondary negative symptoms related to EPS (Figure 10).

Further investigations are warranted to determine if a larger proportion of patients can be benefitted by treatment with

\section{REFERENCES}

Adam, O. R., and Jankovic, J. (2008). Symptomatic treatment of Huntington disease. Neurotherapeutics 5, 181-197. doi: 10.1016/j.nurt.2008.01.008

Addington, J., and Addington, D. (2000). Neurocognitive and social functioning in schizophrenia: a 2.5 year follow-up study. Schizophr. Res. 44, 47-56. doi: 10.1016/S0920-9964(99)00160-7

Alaqeel, B., and Margolese, H. C. (2012). Remission in schizophrenia: critical and systematic review. Harv. Rev. Psychiatry 20, 281-297. doi: 10.3109/10673229.2012.747804

Alaqeel, B., Rej, S., Annable, L., and Margolese, H. C. (2013). "Do second-generation antipsychotics increase remission in schizophrenia? A metaanalysis," in 14th International Congress of Schizophrenia Research (Orlando, FL).

Andreasen, N. C., Carpenter, W. T. Jr., Kane, J. M., Lasser, R. A., Marder, S. R., et al. (2005). Remission in schizophrenia: proposed criteria and rationale for consensus. Am. J. Psychiatry 162, 441-449. doi: 10.1176/appi.ajp.162.3.441

Bobo, W. V. (2013). Asenapine, iloperidone and lurasidone: critical appraisal of the most recently approved pharmacotherapies for schizophrenia in adults. Expert Rev. Clin. Pharmacol. 6, 61-91. doi: 10.1586/ecp. 12.70

De Hert, M., Detraux, J., Van Winkel, R., Yu, W., and Correll, C. U. (2012a). Metabolic and cardiovascular adverse effects associated with antipsychotic drugs. Nat. Rev. Endocrinol. 8, 114-126. doi: 10.1038/nrendo.2011.156
De Hert, M., Yu, W., Detraux, J., Sweers, K., Van Winkel, R., and Correll, C. U. (2012b). Body weight and metabolic adverse effects of asenapine, iloperidone, lurasidone and paliperidone in the treatment of schizophrenia and bipolar disorder: a systematic review and exploratory meta-analysis. CNS Drugs 26, 733-759. doi: 10.2165/11634500000000000-00000

Delay, J., and Deniker, P. (1955). Neuroleptic effects of chlorpromazine in therapeutics of neuropsychiatry. J. Clin. Exp. Psychopathol. $16,104-112$.

Friedman, J. H. (2011). Atypical antipsychotic drugs in the treatment of Parkinson's disease. J. Pharm. Pract. 24, 534-540. doi: 10.1177/0897190011426556

Goldberg, T. E., Goldman, R. S., Burdick, K. E., Malhotra, A. K., Lencz, T., Patel, R. C., et al. (2007). Cognitive improvement after treatment with second-generation antipsychotic medications in first-episode schizophrenia: is it a practice effect? Arch. Gen. Psychiatry 64, 1115-1122. doi: 10.1001/archpsyc.64.10.1115

Green, M. F. (1996). What are the functional consequences of neurocognicomments]. Am. J. Psychiatry 153, 321-330.

Green, M. F., Kern, R. S., Braff, D. L., and Mintz, J. (2000). Neurocognitive deficits and functional outcome in schizophrenia: are we measuring the "right stuff"? Schizophr. Bull. 26, 119-136. doi: 10.1093/oxfordjournals.schbul.a033430

Harvey, P., Siu, C., Cucchiaro, J., Pikalov, A., and Loebel, A. (2013). tive deficits in schizophrenia? [see

AAPDs compared with TAPDs in terms of remission and recovery. Specifically, efforts to develop newer antipsychotic compounds with minimal adverse events associated with some existing AAPDs, e.g., weight gain, cardiovascular symptoms, and hormonal abnormalities, will provide a promising strategy to attain this goal.

\section{ACKNOWLEDGMENTS}

This study was funded by grants-in-aid for Scientific Research from Japan Society for the Promotion of Science, Health and Labour Sciences Research Grants for Comprehensive Research on Disability, Health, and Welfare (H23-Seishin-Ippan002; H24-Seishin-Ippan-002), and SENSHIN Medical Research Foundation.

The author acknowledges Drs. Herbert Y. Meltzer, Philip Harvey, Cynthia Siu, Adrian Newman-Tancredi, and Chika Sumiyoshi for discussions.

"Awareness of illness as a predictor of cooperation with cognitive assessments and cognitive benefits of atypical antipsychotic medication," in 14th Internationa Congress on Schizophrenia Research (Orland, FL).

Harvey, P. D., and Keefe, R. S (1997). Cognitive impairment in schizophrenia and implication of atypical neuroleptic treatment. CNS Spectrums 2, 41-55.

Ichikawa, J., Dai, J., O’laughlin, I. A., Fowler, W. L., and Meltzer, H. Y. (2002). Atypical, but not typical, antipsychotic drugs increase cortical acetylcholine release without an effect in the nucleus accumbens or striatum. Neuropsychopharmacology 26, 325-339. doi: 10.1016/S0893133X(01)00312-8

Jones, P. B., Barnes, T. R., Davies, L. Dunn, G., Lloyd, H., Hayhurst, K. P., et al. (2006). Randomized controlled trial of the effect on quality of life of second- vs first-generation antipsychotic drugs in schizophrenia: cost utility of the latest antipsychotic drugs in schizophrenia study (CUtLASS 1). Arch. Gen. Psychiatry 63, 1079-1087. doi: 10.1001/archpsyc.63.10.1079

Kane, J., Honigfeld, G., Singer, J., Meltzer, H. Y., and Group, C. C. S. (1988). Clozapine for the treatment-resistant schizophrenic: a double-blind comparison with chlorpromazine. Arch. Gen. Psychiatry 45, 789-796. doi: 10.1001/archpsyc.1988.01800330013001

Keefe, R. S., Bilder, R. M., Davis, S. M., Harvey, P. D., Palmer, B. W., Gold, J. M., et al. (2007). Neurocognitive effects of antipsychotic medications in patients with chronic schizophrenia in the CATIE Trial. Arch. Gen. Psychiatry 64, 633-647. doi: 10.1001/archpsyc.64.6.633

Keefe, R. S., Goldberg, T. E., Harvey, P. D., Gold, J. M., Poe, M. P., and Coughenour, L. (2004). The brief assessment of cognition in Schizophrenia: reliability, sensitivity, and comparison with a standard neurocognitive battery. Schizophr. Res. 68, 283-297. doi: 10.1016/j.schres.2003.09.011

Kuroki, H., Meltzer, H. Y., and Ichikawa, J. (1998). Effect of antipsychotic drugs on extracellular dopamine levels in rat medial prefrontalcortex and nucleus accumbens. J. Pharmacol. Exp. Ther. 288, 774-781.

Leucht, S., Corves, C., Arbter, D., Engel, R. R., Li, C., and Davis, J. M. (2009a). Second-generation versus first-generation antipsychotic drugs for schizophrenia: a meta-analysis. Lancet 373, 31-41. doi: 10.1016/S0140-6736(08)61764-X

Leucht, S., Komossa, K., RummelKluge, C., Corves, C., Hunger, H., Schmid, F., et al. (2009b). A meta-analysis of head-to-head comparisons of second-generation antipsychotics in the treatment of schizophrenia. Am. J. Psychiatry 166, 152-163. doi: 10.1176/appi.ajp.2008.08030368

Lieberman, J. A., Stroup, T. S., McEvoy, J. P., Swartz, M. S., Rosenheck, R. A., Perkins, D. O., et al. (2005). Effectiveness of antipsychotic drugs in patients with chronic schizophrenia. N. Engl J. Med. 353, 1209-1223. doi: 10.1056/ NEJMoa051688

Maher, A. R., and Theodore, G. (2012). Summary of the comparative effectiveness review on off-label use of 
atypical antipsychotics. J. Manag. Care Pharm. 18, S1-S20.

Mausbach, B. T., Depp, C. A., Bowie, C. R., Harvey, P. D., McGrath, J. A., Thronquist, M. H., et al. (2011). Sensitivity and specificity of the UCSD Performance-based Skills Assessment (UPSA-B) for identifying functional milestones in schizophrenia. Schizophr. Res. 132, 165-170. doi: 10.1016/j.schres.2011. 07.022

McGlashan, T. H., Zipursky, R. B., Perkins, D., Addington, J., Miller, T., Woods, S. W., et al. (2006). Randomized, double-blind trial of olanzapine versus placebo in patients prodromally symptomatic for psychosis. Am. J. Psychiatry 163, 790-799. doi: 10.1176/appi.ajp.163.5.790

McGorry, P. D., Yung, A. R., Phillips, L. J., Yuen, H. P., Francey, S., Cosgrave, E. M., et al. (2002). Randomized controlled trial of interventions designed to reduce the risk of progression to first-episode psychosis in a clinical sample with subthreshold symptoms. Arch. Gen. Psychiatry 59, 921-928. doi: 10.1001/archpsyc.59.10.921

Melnik, T., Soares, B. G., Puga, M. E., and Atallah, A. N. (2010). Efficacy and safety of atypical antipsychotic drugs (quetiapine, risperidone, aripiprazole and paliperidone) compared with placebo or typical antipsychotic drugs for treating refractory schizophrenia: overview of systematic reviews. Sao Paulo Med. J. 128, 141-166. doi: 10.1590/S151631802010000300007

Meltzer, H. Y. (1989). Clinical studies on the mechanism of action of clozapine: the dopamine- serotonin hypothesis of schizophrenia. Psychopharmacology (Berl) 99, S18-S27 doi: 10.1007/BF00442554

Meltzer, H. Y. (1991a). The mechanism of action of novel antipsychotic drugs. Schizophr. Bull. 17, 263-287. doi: 10.1093/schbul/17.2.263

Meltzer, H. Y. (1991b). The neurobiology of schizophrenia. Curr. Opin. Psychiatry 4, 90-95. doi: 10.1097/00001504-19910200000021

Meltzer, H. Y. (2013). Update on typical and atypical antipsychotic drugs. Annu. Rev. Med. 64, 393-406. doi: 10.1146/annurev-med-050911161504

Meltzer, H. Y., Li, Z., Kaneda, Y., and Ichikawa, J. (2003). Serotonin receptors: their key role in drugs to treat schizophrenia. Prog.
Neuropsychopharmacol. Biol. Psychiatry 27, 1159-1172. doi: 10.1016/j.pnpbp.2003.09.010

Meltzer, H. Y., Matsubara, S., and Lee, J. C. (1989). Classification of typical and atypical antipsychotic drugs on the basis of dopamine D-1, D-2 and serotonin2 pKi values. J. Pharmacol. Exp. Ther. 251, 238-246.

Meltzer, H. Y., Park, S., and Kessler, R. (1999). Cognition, schizophrenia, and the atypical antipsychotic drugs. Proc. Nat. Acad. Sci. U.S.A. 96, 13591-13593. doi: 10.1073/pnas.96.24.13591

Meyer, J. M., Loebel, A. D., and Schweizer, E. (2009). Lurasidone: a new drug in development for schizophrenia. Expert. Opin. Investig. Drugs 18, 1715-1726. doi: 10.1517/13543780903286388

Mohamed, S., Rosenheck, R., Lyketsos, C. G., Kaczynski, R., Sultzer, D. L., and Schneider, L. S. (2012). Effect of second-generation antipsychotics on caregiver burden in Alzheimer's disease. J. Clin. Psychiatry 73, 121-128. doi: 10.4088/JCP.10m06574

Newman-Tancredi, A., and Kleven, M. S. (2011). Comparative pharmacology of antipsychotics possessing combined dopamine D2 and serotonin 5-HT1A receptor properties. Psychopharmacology 216, 451-473. doi: 10.1007/s00213-011-2247-y

Oliveira, I. R., Nunes, P. M., Coutinho, D. M., and Sena, E. P. (2009). Review of the efficacy of placebo in comparative clinical trials between typical and atypical antipsychotics. Rev. Bras. Psiquiatr 31, 52-56. doi: 10.1590/S151644462009000100013

Pietrzak, R. H., Olver, J., Norman, T., Piskulic, D., Maruff, P., and Snyder, P. J. (2009). A comparison of the CogState schizophrenia battery and the measurement and treatment research to improve cognition in schizophrenia (MATRICS) battery in assessing cognitive impairment in chronic schizophrenia. J. Clin. Exp. Neuropsychol. 31, 848-859. doi: $10.1080 / 13803390802592458$

Saeedi, H., Remington, G., and Christensen, B. K. (2006). Impact of haloperidol, a dopamine D2 antagonist, on cognition and mood. Schizophr. Res. 85, 222-231. doi: 10.1016/j.schres.2006.03.033

Seeman, P., Schwarz, J., Chen, J. F., Szechtman, H., Perreault, M., McKnight, G. S., et al. (2006). Psychosis pathways converge via D2high dopamine receptors. Synapse 60, 319-346. doi: 10.1002/syn.20303

Spielmans, G. I., Berman, M. I., Linardatos, E., Rosenlicht, N. Z. Perry, A., and Tsai, A. C. (2013). Adjunctive atypical antipsychotic treatment for major depressive disorder: a meta-analysis of depression, quality of life, and safety outcomes. PLoS Med. 10:e1001403. doi: 10.1371/journal.pmed.1001403

Stockmeier, C. A., Dicarlo, J. J., Zhang, Y., Thompson, P., and Meltzer, $\mathrm{H}$ Y. (1993). Characterization of typical and atypical antipsychotic drugs based on in vivo occupancy of serotonin $_{2}$ and dopamine 2 receptors. J. Pharmacol. Exp. Ther. 266, 1374-1384.

Sumiyoshi, T. (2008). A possible doseside effect relationship of antipsychotic drugs: relevance to cognitive function in schizophrenia. Expert Rev. Clin. Pharmacol. 1, 791-802. doi: 10.1586/17512433.1.6.791

Sumiyoshi, T., Miyanishi, T., Harvey, P., Siu, C., Loebel, A., and Ogasa, M. (2013). "Cognitive performance in patients with schizophrenia treated with lurasidone: results from a placebo- and active-controlled acute phase study followed by a 6 month double-blind extension," in $3 r d$ Asian Congress on Schizophrenia Research (Bali).

Sumiyoshi, T., Suzuki, K., Sakamoto, H., Yamaguchi, N., Mori, H., Shiba, K., et al. (1995). Atypicality of several antipsychotics on the basis of in vivo dopamine- $\mathrm{D}_{2}$ and serotonin-5 $5 \mathrm{HT}_{2}$ receptor occupancy. Neuropsychopharmacology $12,57-64$.

Swerdlow, N. R., Braff, D. L., Taaid, N., and Geyer, M. A. (1994). Assessing the validity of an animal model of deficient sensorimotor gating in schizophrenic patients. Arch. Gen. Psychiatry 51, 139-154. doi: 10.1001/archpsyc. 1994.03950020063007

Takeuchi, H., Suzuki, T., Uchida, H., Watanabe, K., and Mimura, M. (2012). Antipsychotic treatment for schizophrenia in the maintenance phase: a systematic review of the guidelines and algorithms. Schizophr. Res. 134, 219-225. doi 10.1016/j.schres.2011.11.021

Toru, M., Kurumaji, A., and Ishimaru, M. (1994). Excitatory amino acids: implications for psychiatric disorders research Life Sci. 55, 1683-1699. doi: 10.1016/0024-3205(94)00337-8

Veselinovic, T., Schorn, H., Vernaleken, I. B., Hiemke, C., Zernig, G.,
Gur, R., and Grunder, G. (2013). Effects of antipsychotic treatment on cognition in healthy subjects. J. Psychopharmacol. 27, 374-385. doi: $10.1177 / 0269881112466183$

Weickert, T. W., Goldberg, T. E., Marenco, S., Bigelow, L. B., Egan, M. F., and Weinberger, D. R. (2003). Comparison of cognitive performances during a placebo period and an atypical antipsychotic treatment period in schizophrenia: critical examination of confounds. Neuropsychopharmacology 28, 1491-1500. doi: 10.1038/ sj.npp. 1300216

Woodward, N. D., Purdon, S. E., Meltzer, H. Y., and Zald, D. H. (2005). A meta-analysis of neuropsychological change to clozapine, olanzapine, quetiapine, and risperidone in schizophrenia. Int. J. Neuropsychopharmacol. 8, 457-472. doi: 10.1017/S1461145705 00516X

Zhang, J. P., Gallego, J. A., Robinson, D. G., Malhotra, A. K., Kane, J. M., and Correll, C. U. (2013). Efficacy and safety of individual second-generation vs. first-generation antipsychotics in first-episode psychosis: a systematic review and meta-analysis. Int. J. Neuropsychopharmacol. 16, 1205-1218. doi: 10.1017/ S1461145712001277

Conflict of Interest Statement: The author has received advisory board and/or speaker's honoraria from Dainippon-Sumitomo, Yoshitomiyakuhin, Tanabe-Mitsubishi, Otsuka, Eli Lilly, and Takeda Pharmaceuticals.

Received: 13 June 2013; accepted: 30 July 2013; published online: 26 August 2013. Citation: Sumiyoshi T (2013) Antipsychotic treatments; focus on lurasidone. Front. Pharmacol. 4:102. doi: 10.3389/fphar.2013.00102

This article was submitted to Neuropharmacology, a section of the journal Frontiers in Pharmacology. Copyright (c) 2013 Sumiyoshi. This is an open-access article distributed under the terms of the Creative Commons Attribution License (CC BY). The use, distribution or reproduction in other forums is permitted, provided the original author(s) or licensor are credited and that the original publication in this journal is cited, in accordance with accepted academic practice. No use, distribution or reproduction is permitted which does not comply with these terms. 